\begin{tabular}{cc|c}
\hline Tar. Bil. Der. & Tarım Bilimleri Dergisi & Journal of Agricultural Sciences \\
& $\begin{array}{c}\text { Dergi web sayfası: } \\
\text { www.agri.ankara.edu.tr/dergi }\end{array}$ & Journal homepage: \\
& www.agri.ankara.edu.tr/journal
\end{tabular}

\title{
Effect of Pregelatinization and Retrogradation on Some Physicochemical Changes of Wheat-Potato Starches
}

\author{
Nesimi AKTAŞ̧, Kamil Emre GERÇEKASLAN ${ }^{a}$ \\ ${ }^{a}$ Nevşehir Hacı Bektaş Veli University, Faculty of Engineering Architecture, Department of Food Engineering, 50300, Nevşehir, \\ TURKEY
}

\section{ARTICLE INFO}

Research Article

DOI: 10.15832 /ankutbd.426252

Corresponding Author: Nesimi AKTAŞ, E-mail: naktas@nevsehir.edu.tr, Tel: +90 (384) 2281000

Received: 23 May 2018, Received in Revised Form: 28 June 2018, Accepted: 15 July 2018

\begin{abstract}
The freezable (FW) and unfreezable water (UFW) contents of wheat and potato starches and their physically modified forms [pregelatinized (PGS) and retrograded (RS)] were analyzed by Differential Scanning Calorimetry (DSC) at various hydration levels $(25,35,45,55,65,75$ and $85 \%)$. In all the starch samples, the UFW content increased with increasing hydration level. Potato starch samples (native, pregelatinized and retrograded) had higher UFW contents than wheat starch samples at all hydration levels. Similarly, with the increase of hydration level in all starch samples, onset $\left(\mathrm{T}_{\mathrm{o}}\right)$, peak $\left(\mathrm{T}_{\mathrm{p}}\right)$ and endset $\left(\mathrm{T}_{\mathrm{e}}\right)$ temperatures of the peaks also increased. It was obtained that physical modifications in starches had significant effects $(\mathrm{P}<0.05)$ on water absorption index (WAI) and water solubility index (WSI) of starch samples. The highest WAI (10.51) and WSI (2.31) values were determined in pregelatinized potato starches. Rapid Visco Analyzer (RVA) profiles revealed that physically modified starches had higher viscosity values than native starches. The results clearly showed that pregelatinization and retrogradation had positive effects on the physicochemical properties studied.
\end{abstract}

Keywords: Unfreezable water; Wheat-potato starch; Physical modifications; DSC; RVA

(C) Ankara Üniversitesi Ziraat Fakültesi

\section{Introduction}

Starch affects texture, viscosity, gel structure, gel formation, adhesion, binding, water holding capacity, film formation and product homogeneity (Kaur et al 2012; Fu et al 2014). Because of low shear resistance, thermal resistances, thermal decompositions and high retrogradation tendency, the use of native starches is limited in some industrial food applications. Thus, there is a need to make some modifications to enhance the functional properties of starch (Gryszkin et al 2016). The modifications in starches can be carried out in three different ways: chemical (derivatization, acid thinning/hydrolytic depolymerization, dextrinization, oxidation, hydrolysis), physical (pregelatinized and granular cold-water-swelling starches) and genetic (waxy starches, high-amylose starches) (Ashogbon \& Akintayo 2014; Kaur \& Singh 2015). Since starches are not treated with any chemicals in physical modification, these starches are safe for human consumption and, therefore, more preferred (Kaur et al 2012; Huang et al 2016).

Physical modifications of the native starch granules involve different temperature/moisture 
combinations, shear, pressure, and irradiation. These modifications also include mechanical abrasion to change the physical size of starch granules (Ashogbon \& Akintayo 2014). Physical modifications affect physicochemical properties such as chemical reactivity, solubility, swelling power, pasting properties, thermal stability, gelatinization and retrogradation characteristics. (Huang et al 2016; Wang et al 2016). Pregelatinization process is the one of the most common methods of physical modification of starch and widely used in food industry (Zia-ud-Din et al 2017). Because of pregelatinized starch quickly hydrates and swells in water without heating, it is commonly used as a thickening agent in instant soups, instant desserts and baby foods (Ashogbon \& Akintayo 2014).

The physical and structural properties of starch vary depending on the interactions of water and starch molecule. Starch-water interactions can be detected by changes in the physical state of the water, commonly analyzed by DSC. The physical state of water in starch can be described as freezable (free) and unfreezable (bound) water. The UFW is strongly bound to starch molecules and it does not act as a solvent for solutes, such as free water. This water cannot be frozen even at very low sub-zero temperatures, and significantly affects the stability of starch-based products. Determining the content of UFW in dehydrated foods also provides important information in both establishing appropriate process conditions and determining storage conditions (Suzuki \& Kitamura 2008; Fu et al 2014). FW and UFW content by DSC can be studied across a wider range of moisture and temperature than most techniques. Although there is a great deal of research on starch gelatinization (Fredriksson et al 1998; Wang et al 2014), the number of studies on starchwater interactions is limited. In that way, the aim of this study was: (1) to determine the FW and UFW contents of wheat and potato starches both native and physically modified forms (pregelatinized and retrograded) at different hydration levels by means of DSC, (2) to define water absorption-water solubility indexes and (3) to determine the RVA properties of all the starches.

\section{Material and Methods}

\subsection{Materials}

Native wheat (NWS, moisture content $12.9 \%$ ) and potato starches (NPS, moisture content 16.6\%) used as material were purchased from Soyyigit Food Co., Ltd. (İstanbul, Turkey). Pregelatinized wheat (PGWS), pregelatinized potato (PGPS), retrograded wheat (RWS) and retrograded potato (RPS) starches were obtained from these starches by using the physical modification technique indicated in the method section.

\subsection{Preparation of pregelatinized-retrograded starches and determination of pasting properties}

The $8 \%$ suspensions $(\mathrm{w} / \mathrm{w})$ of wheat and potato starch samples were prepared in RVA tubes with distilled water and the samples were loaded into the RVA (RVA 4500, Perten, Sweden). The prepared suspensions were stirred in the RVA at $400 \mathrm{rpm}$ for $10 \mathrm{~s}$ and then held for $10 \mathrm{~min}$ at $30^{\circ} \mathrm{C}$. Then, they were heated up to $95^{\circ} \mathrm{C}$ at $10.83{ }^{\circ} \mathrm{C} \mathrm{min}-1$ and held for at this temperature for $5 \mathrm{~min}$. The samples were cooled from $95{ }^{\circ} \mathrm{C}$ to $50{ }^{\circ} \mathrm{C}$ in 4 min and kept at this temperature for $10 \mathrm{~min}$. PGS samples were obtained at viscosity peak (peak viscosity and peak temperature values for wheat starch 104 RVU, 95 ${ }^{\circ} \mathrm{C}$; for potato starch $787 \mathrm{RVU}, 80{ }^{\circ} \mathrm{C}$, respectively) from the RVA profile, while RS samples were obtained after being stored for $120 \mathrm{~h}$ at $4{ }^{\circ} \mathrm{C}$ of the completed RVA samples (Yglesias \& Jackson 2005). After the mentioned periods, the samples were frozen by adding liquid nitrogen, and then freeze drying were carried out in the freeze drier (Operon FDU-8612, Korea). The dried samples were ground by using a $1 \mathrm{~mm}$ mesh screened cyclone mill (Retsch ZM 200, Germany) for the analysis. The moisture content of the prepared starch samples was determined by the oven drying method in an oven at $105^{\circ} \mathrm{C}$ for $24 \mathrm{~h}$. Starch concentration of the slurry used in pasting analyses was adjusted to $8 \%$, and the pasting properties of starch samples (native pregelatinized and retrograded) were determined by applying the above-mentioned RVA procedure. The RVA parameters (initial, peak, trough, breakdown, 
final and setback viscosity) were obtained from the RVA viscogram data according to Ragaee \& AbdelAal (2006).

\subsection{Water absorption and water solubility indexes}

The WAI and WSI of the samples (NWS, PGWS, RWS, NPS, PGPS and RPS) were determined based on the method described by Anderson et al (1969). Briefly, $2.5 \mathrm{~g}$ sample was weighed into $50 \mathrm{~mL}$ tared centrifuge tubes, and $30 \mathrm{~mL}$ distilled water was added to form a suspension. The prepared samples were centrifuged (Hanil Combi 514R, Korea) at $3000 \mathrm{~g}$ for 10 minutes. Then, the supernatant was carefully transferred to tared drying vessels and dried $105{ }^{\circ} \mathrm{C}$ for $12 \mathrm{~h}$ in a drying cabinet. The pellet in centrifuge tube was weighed and WAI was calculated according to Equation 1. Water solubility index (WSI) in dried samples was calculated according to Equation 2.

$$
\begin{aligned}
& W A I=\frac{\text { pellet weight }(\mathrm{g})}{\text { dry weight of original starch }(\mathrm{g})} \\
& W S I=\frac{\text { weight after drying }(\mathrm{g})}{\text { dry weight of original starch }(\mathrm{g})}
\end{aligned}
$$

\subsection{Freezable and unfreezable water contents}

The DSC studies were conducted on samples at various hydration levels $(25,35,45,55,65,75$ and $85 \%$ ). For this purpose, accurately $10 \mathrm{mg}$ samples were weighed into the hermetic DSC pans (product number 03190029, Perkin Elmer, USA), and then distilled water was added with a micro syringe to obtain the desired hydration-level samples. Pans were sealed and weighed (BEL, M214Ai, Italy). The sealed pans were kept for $24 \mathrm{~h}$ at room temperature to ensure homogenous distribution of water. The FW and UFW contents of the samples were determined by using the DSC (DSC 6000, Perkin Elmer, USA) with an intercooler system. The temperature and heat flow calibration of the DSC were performed by using indium (melting point: $156.6^{\circ} \mathrm{C}, \Delta \mathrm{H}=$ $28.47 \mathrm{~J} \mathrm{~g}^{-1}$ ) and water (melting point: $0^{\circ} \mathrm{C}, \Delta \mathrm{H}=$ $333.20 \mathrm{~J} \mathrm{~g}^{-1}$ ). An empty pan was used as reference. The following temperature program was used to determine FW and UFW contents of samples: (1) cooling from $20{ }^{\circ} \mathrm{C}$ to $-80{ }^{\circ} \mathrm{C}$ at $5{ }^{\circ} \mathrm{C} \mathrm{min}{ }^{-1}$. cooling rate; (2) holding at $-80{ }^{\circ} \mathrm{C}$ for 5 min.; (3) heating from $-80{ }^{\circ} \mathrm{C}$ to $50{ }^{\circ} \mathrm{C}$ at $5{ }^{\circ} \mathrm{C} \mathrm{min}$. . heating rate. To determine the FW and UFW contents of the samples at the end of the DSC analyses, the method described by Fu et al (2014) was used. The method contains the ratio of the area corresponding to the melting enthalpy of the ice in the material to the pure water melting enthalpy (333.20 $\left.\mathrm{J} \mathrm{g}^{-1}\right)$. UFW content was defined by using equation 3 . The exact moisture content of each sample was confirmed after collecting the calorimetric data. The sealed DSC pans were punctured and dried in an oven at $105^{\circ} \mathrm{C}$ for $24 \mathrm{~h}$ and the reweighed to determine the exact water content in the sample.

Unfreezable water content $=\frac{m_{w}}{m_{s}}-\frac{\Delta H_{s}}{\Delta H_{w}}$

Unfreezable water content: (g water/g dry starch); $m_{w}$, water content in samples (g); $m_{s}$, dry starch in samples $(\mathrm{g}) ; \Delta H_{s}$, the ice melting enthalpies of moisture in starch samples $\left(\mathrm{J} \mathrm{g}^{-1}\right) ; \Delta H_{w}$, the ice melting enthalpy pure water $\left(\mathrm{J} \mathrm{g}^{-1}\right)$.

\subsection{Statistical analysis}

All the tests in the study were carried out in triplicate and the results were reported as mean values \pm and standard deviations. The acquired data were subjected to analysis of variance by using SPSS 22.0 (IBM Corp., Armonk, NY, USA) package program, and the average values of meaningful main variance sources were compared using Duncan's multiple comparison tests at $5 \%$.

\section{Results and Discussion}

\subsection{Water absorption and water solubility indexes}

The WAI and WSI of the studied starches are given in Table 1. As can be seen the Table 1, the WSI values of physically modified starch samples were significantly higher than those of the NS samples $(\mathrm{P}<0.05)$. Similarly, the PGPS samples had higher WSI values than those of the RS samples. The highest WAI value were obtained in PGPS. The 
highest WAI values of the PGS may be explained by the fact that the water is much more and much better bound to the swollen granules. This may also be explained for potato starch by the repulsion between the phosphate groups weakly bonded in the crystalline structure and thus the further swelling. A similar situation was reported by Wang et al (2014). Also, Ashogbon \& Akintayo (2014) emphasized that the PGS had higher water absorption and water solubility properties than native starches.

Table 1- The water absorption and water solubility indexes of starch samples

\begin{tabular}{lrc}
\hline Starch & WAI & WSI \\
\hline Wheat & $0.69 \pm 0.00^{\mathrm{e}}$ & $0.26 \pm 0.00^{\mathrm{b}}$ \\
Pregelatinized wheat & $6.08 \pm 0.08^{\mathrm{b}}$ & $2.07 \pm 0.05^{\mathrm{a}}$ \\
Retrograded wheat & $5.68 \pm 0.04^{\mathrm{c}}$ & $2.07 \pm 0.02^{\mathrm{a}}$ \\
Potato & $0.69 \pm 0.00^{\mathrm{e}}$ & $0.37 \pm 0.04^{\mathrm{b}}$ \\
Pregelatinized potato & $10.51 \pm 0.26^{\mathrm{a}}$ & $2.31 \pm 0.64^{\mathrm{a}}$ \\
Retrograded potato & $3.47 \pm 0.02^{\mathrm{d}}$ & $1.97 \pm 0.03^{\mathrm{a}}$ \\
\hline a, e, mean values in the same column with the same superscript \\
letter are not significantly different $(\mathrm{P}<0.05) ;$ mean values $(\mathrm{n}=3)$ \\
\pm standard deviation
\end{tabular}

The WAI and WSI values of the RWS samples were significantly higher than those of the NWS samples $(\mathrm{P}<0.05)$. The high WAI and WSI values determined in RWS may due to the appearance of B-type crystalline structure. Wang et al (2015) reported that the RS had a typical B-type XRD pattern, irrespective of whether it was present as A- or B-type polymorphs in its native state. There are four or eight water molecules per unit cell in A-type polymorphs whereas 36 water molecules per unit cell are in B type polymorphs (Bogracheva et al 2002).

\subsection{RVA profiles}

The RVA results for the starch samples are shown in Table 2. As can be seen in Table 2, the PGPS had the greatest initial viscosity value (the viscosity value at the starting point of gelation) than those of the other starch samples. It was also found that each form of the potato starch (NPS, PGPS, RPS) had higher $(\mathrm{P}<0.05)$ peak, trough, breakdown and final viscosity values than the wheat starches. The finding of our study were agreed with the results reported by Jane et al (1999). The researchers reported that the peak, trough and final viscosity values of potato starch were higher than wheat starch, while the setback viscosity value of potato starch was lower than that of wheat starch. Higher viscosity values in potato starches as compared to wheat starches may be attributed to that the potato starch contains more amylopectin and phosphate esters. While potato starch contains about $80 \%$ amylopectin (Hovenkamp-Hermelink et al 1988), wheat starch contains about $72 \%$ amylopectin (Fredriksson et al 1998). While amylopectin significantly affects the swelling and pasting properties of starch granules, lipids and amylose inhibit swelling (Jane et al 1999). Singh et al (2003) reported that properties of starch pastes in aqueous systems depend on the physical and chemical characteristics of the starch granules, such as granule size distribution, mean granule size, mineral content, and amylose/amylopectin ratio. There are phosphate monoesters covalently bonded to the amylopectin fraction of starch in potato starches and these groups lead to an increase in starch viscosity, while wheat starches have higher phospholipid contents and results in lower-viscosity pastes. Moreover, Gomand et al (2010) reported that chain length distribution had significant effect on the RVA properties in potato and cassava starches and indicated that both peak viscosity and breakdown viscosity increased with higher levels of short chains and lower levels of long chains. The researcher also noted that higher levels of short chains resulted in less regular lamellar structure formation, allowing easier penetration of water into the crystalline zones of the granules, and thus higher peak viscosity. As shown in Table 2, the potato starch samples produced higher $(\mathrm{P}<0.05)$ breakdown drop as compared to the wheat starches. Pasting properties of starches vary depending on amylose/amylopectin ratio, size, swelling power, and rigidity of the granule. Viscosity breakdown is considered as a measure of granule degradation and the stability of the paste (Huang et al 2015). During breakdown, the swollen granules are destroyed, and most of the amylose 
Table 2- The viscosity values of starch samples

\begin{tabular}{lrrrrrr}
\hline \multirow{2}{*}{ Starch } & \multicolumn{5}{c}{ Viscosity $($ RVU) } \\
\cline { 2 - 7 } & \multicolumn{1}{c}{ Initial } & Peak & Trough & Breakdown & Final & Setback \\
\hline Wheat & $2.00 \pm 0.00^{\mathrm{e}}$ & $104.67 \pm 0.58^{\mathrm{e}}$ & $75.33 \pm 0.57^{\mathrm{e}}$ & $30.00 \pm 0.00^{\mathrm{d}}$ & $167.83 \pm 0.29^{\mathrm{d}}$ & $92.67 \pm 0.58^{\mathrm{c}}$ \\
Pregelatinized wheat & $9.00 \pm 0.00^{\mathrm{b}}$ & $91.00 \pm 1.00^{\mathrm{f}}$ & $74.66 \pm 0.58^{\mathrm{e}}$ & $16.00 \pm 0.00^{\mathrm{e}}$ & $115.50 \pm 0.50^{\mathrm{f}}$ & $40.57 \pm 0.60^{\mathrm{d}}$ \\
Retrograded wheat & $6.00 \pm 0.00^{\mathrm{c}}$ & $110.66 \pm 0.57^{\mathrm{d}}$ & $100.93 \pm 0.12^{\mathrm{d}}$ & $10.00 \pm 0.00^{\mathrm{f}}$ & $130.83 \pm 0.76^{\mathrm{e}}$ & $30.00 \pm 0.00^{\mathrm{e}}$ \\
Potato & $1.00 \pm 0.00^{\mathrm{f}}$ & $787.00 \pm 1.00^{\mathrm{b}}$ & $200.43 \pm 0.75^{\mathrm{a}}$ & $587.00 \pm 1.00^{\mathrm{b}}$ & $208.80 \pm 0.75^{\mathrm{c}}$ & $8.97 \pm 0.06^{\mathrm{f}}$ \\
Pregelatinized potato & $106.97 \pm 0.45^{\mathrm{a}}$ & $462.83 \pm 0.29^{\mathrm{c}}$ & $158.00 \pm 0.00^{\mathrm{c}}$ & $304.97 \pm 0.25^{\mathrm{c}}$ & $271.73 \pm 0.75^{\mathrm{b}}$ & $113.57 \pm 0.51^{\mathrm{a}}$ \\
Retrograded potato & $3.00 \pm 0.00^{\mathrm{d}}$ & $1016.67 \pm 1.53^{\mathrm{a}}$ & $180.07 \pm 0.40^{\mathrm{b}}$ & $836.66 \pm 0.57^{\mathrm{a}}$ & $286.43 \pm 0.51^{\mathrm{a}}$ & $105.93 \pm 0.40^{\mathrm{b}}$ \\
\hline a, f, mean values in the same column with the same superscript letter are not significantly different $(\mathrm{P}<0.05) ;$ mean values $(\mathrm{n}=3) \pm$ \\
standard deviation
\end{tabular}

molecules pass into the solution. The height of the peaks at a given concentration reflects the ability to swell freely of the granules. Potato starch has the ability to swell higher than cereal starches and is less resistant to breakdown during cooking. For this reason, a larger decrease in the viscosity is obtained after reaching the maximum viscosity value (Colussi et al 2017).

Setback values of starch samples are shown in Table 2. The setback values of PGWS and RWS were significantly lower than that of the NWS, but higher in NPS $(\mathrm{P}<0.05)$. The increase in viscosity during cooling is called setback. This increase may be due to the reduction in system energy in addition to amylose association (Alamri et al 2013). Setback is considered to be a measure of gelling ability or retrogradation tendency of starch (Huang et al 2015). High setback values in starches are positively correlated with amylose content of starch, while gelatinization temperature and peak viscosity are inversely related to the amylose content of the starch.

Final viscosity values of starch samples are shown in Table 2 . The values were significantly different from each other $(\mathrm{P}<0.05)$, and the highest value was obtained in the RPS. Increase in the final viscosity provides information on the extent of the formation of the starch-lipid complexes (Blazek \& Copeland 2009). Final viscosity also indicates the ability of the starch to form a viscous paste or gel after cooking and cooling (Cozzolino 2016).

\subsection{Freezable and unfreezable water contents}

The $\mathrm{T}_{\mathrm{o}}, \mathrm{T}_{\mathrm{p}}$ and $\mathrm{T}_{\mathrm{e}}$ values of the endotherms (except for NPS with $25 \%$ moisture content) obtained from starch samples are shown in Table 3. As can be seen in Table 3, in general, the $T_{o}, T_{p}$ and $T_{e}$ values of all the samples studied were significantly different from each other $(\mathrm{P}<0.05)$. With the increase in hydration level, these temperatures were shifted toward higher values. Similar results were reported by Suzuki \& Kitamura (2008), Grunina et al (2015) and Tananuwong \& Reid (2004). The NS had higher $(\mathrm{P}<0.05) \mathrm{T}_{\mathrm{o}}$ values than those of the PGS and RS at hydration levels above $35 \%$ (Table 3). At the hydration levels lower than $65 \%$, the $\mathrm{T}_{\mathrm{o}}$ values of the peak belonging to freezable water in all of the physically modified starches (except for PGPS) were lower than $0{ }^{\circ} \mathrm{C}$. Similar results were reported by Grunina et al (2015), and researchers stressed that the lower $T_{0}$ values were due to the presence of a higher fraction of small size water cluster in these systems. As can be seen from the Table 3 , the $T_{p}$ and $T_{e}$ values of PGS' in comparison to their respective of native starches generally shifted to higher temperatures as the moisture content increased. In the case of RS, the $T_{p}$ values generally were decreased, while the $T_{e}$ values were increased. Achieving higher $T_{p}$ and $T_{e}$ values in pregelatinized starches may be attributed to the establishment of better molecular interactions between water and modified starches.

The UFW contents calculated from the melting enthalpy of ice in the different hydration levels are 


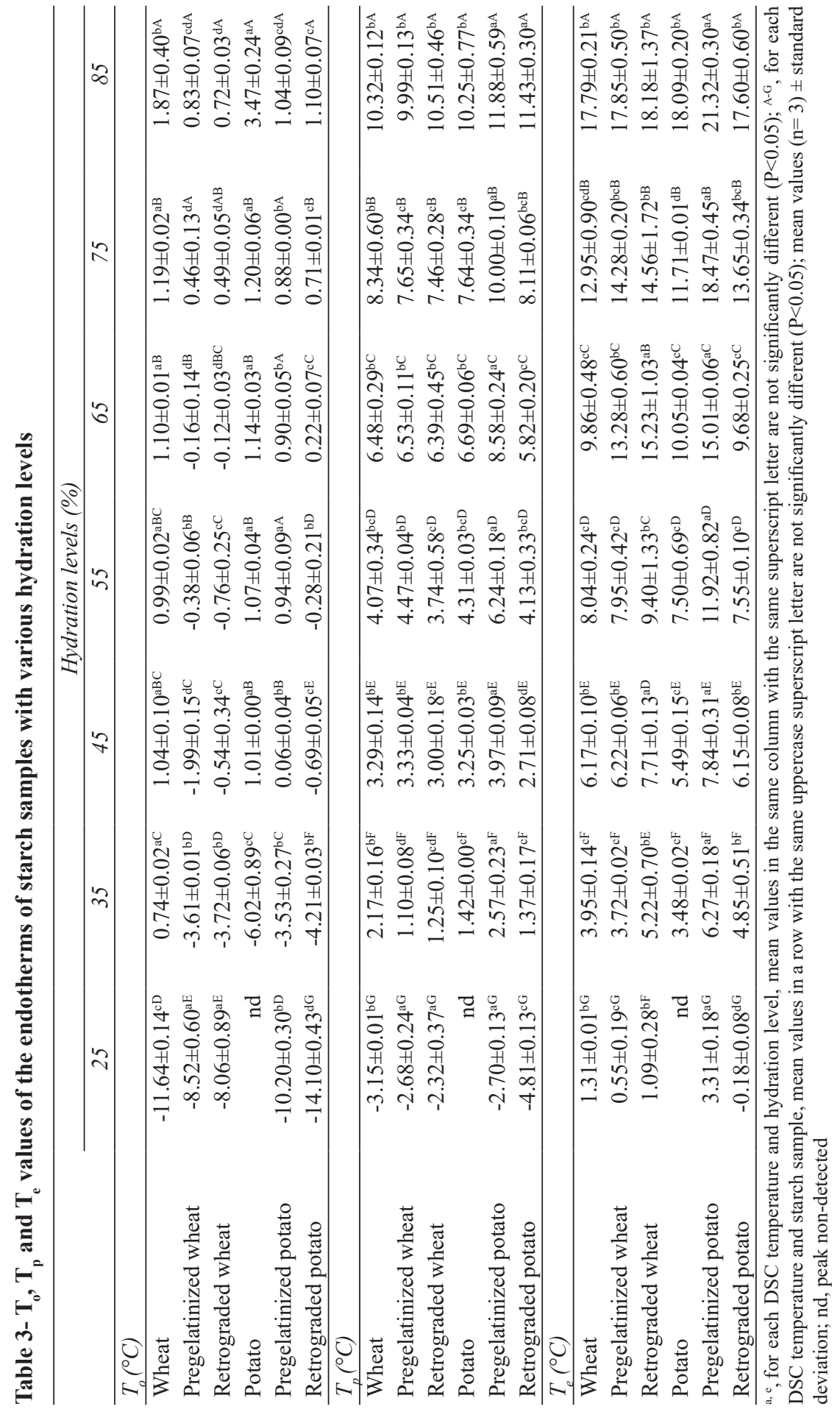


given in Table 4. As can be seen in Table 4, the type of starch and hydration level had a significantly effect on the UFW content $(\mathrm{P}<0.05)$. This may due to the fact that the numbers of available water binding sites of all starches are different. The main binding sites of the starches are hydroxyl groups and inter-glucose oxygen atom. The availability of these regions to interact with water varies depending on the structural and compositional properties of the starches (Fu et al 2014). Hydrogen bonds can be formed between the water molecules and the hydroxyl groups of the starch, and the number of these bonds increases with increasing moisture content up to certain moisture content. The differences between UFW content of starches from different sources may also be due to differences in morphological structure of starch granules. AlcazarAlay \& Meireles (2015) reported that waterbinding capacity was significantly related to the morphological characteristics, such as shape and size of the starch granules.

The UFW contents of physically modified starches were higher than those of the NS in hydration levels up to $35 \%$, while the UFW contents were lower than those of the NS samples in hydration levels above 35\% (Table 4). Similarly, $\mathrm{Fu}$ et al (2014) reported lower UFW content in the gelatinized starch samples. The researchers attributed the decrease in the UFW content to the decrease in water binding sites due to starch-lipid interaction. In hydration levels above $55 \%$, the
PGS had higher $(\mathrm{P}<0.05)$ UFW contents than those of the RS (except for $85 \%$ hydration level PGWS). This is an indication that the PGS can establish better starch-water interactions. Fu et al (2014) reported that the gelatinization process destroyed the weak bonds in the amorphous regions of the granules and thus increased the hydration property of the starch molecules. Similarly, Tananuwong \& Reid (2004) determined that when the starch was heated, the amount of UFW was increased, and fully gelatinized starch samples contained more UFW content than the partially gelatinized starch samples.

As the hydration level increased, there was an increase in the UFW content of NS. Eliasson \& Gudmundsson (2006) indicated that the NS granules swell completely at the hydration level approximately $55 \%$. However, in this research, it was determined that there was significant increase in hydration levels above 55\%. Tang et al (2001) reported that increasing the water concentration in starches caused the appearance of intergranular water, and the thermal properties of this water significantly differed from that of intragranular water. For the practical consequences these results suggest that controlling the amount of freezable water is more important for moisture contents above $30 \%$ considering that only low amounts of freezable water detected in limited water systems.

Table 4- The unfreezable water contents of the starch samples with various hydration levels (g water/g dry starch $\mathbf{x 1 0 0 )}$

\begin{tabular}{|c|c|c|c|c|c|c|c|}
\hline \multirow{2}{*}{ Starch } & \multicolumn{7}{|c|}{ Hydration levels (\%) } \\
\hline & 25 & 35 & 45 & 55 & 65 & 75 & 85 \\
\hline Wheat & $27.63 \pm 0.48^{\mathrm{dG}}$ & $30.48 \pm 0.47^{\mathrm{eF}}$ & $37.01 \pm 0.07^{\mathrm{dE}}$ & $50.77 \pm 0.29^{\mathrm{cD}}$ & $54.67 \pm 0.54^{\mathrm{cC}}$ & $60.73 \pm 0.16^{\mathrm{dB}}$ & $99.92 \pm 2.81^{\mathrm{bA}}$ \\
\hline Pregelatinized wheat & $30.49 \pm 0.32^{\mathrm{cG}}$ & $33.14 \pm 0.14^{\mathrm{dF}}$ & $35.45 \pm 0.08^{\mathrm{eE}}$ & $38.25 \pm 0.17^{\mathrm{dD}}$ & $45.56 \pm 0.24^{\mathrm{dC}}$ & $54.87 \pm 0.07^{\mathrm{eB}}$ & $59.79 \pm 0.09^{\mathrm{eA}}$ \\
\hline Retrograded wheat & $30.02 \pm 0.02^{\mathrm{cG}}$ & $33.45 \pm 0.38^{\mathrm{dF}}$ & $35.56 \pm 0.06^{\mathrm{eE}}$ & $38.78 \pm 0.36^{\mathrm{dD}}$ & $43.39 \pm 0.32^{\mathrm{eC}}$ & $45.47 \pm 0.18^{\mathrm{fB}}$ & $70.81 \pm 0.48^{\mathrm{dA}}$ \\
\hline Potato & nd & $42.26 \pm 0.27^{\mathrm{bF}}$ & $48.70 \pm 0.08^{\mathrm{aE}}$ & $58.89 \pm 0.57^{\mathrm{aD}}$ & $69.94 \pm 0.09^{\mathrm{aC}}$ & $89.58 \pm 1.18^{\mathrm{aB}}$ & $123.57 \pm 1.01^{\mathrm{aA}}$ \\
\hline Pregelatinized potato & $32.87 \pm 0.74^{\mathrm{bF}}$ & $35.10 \pm 0.35^{\mathrm{cE}}$ & $38.79 \pm 0.10^{\mathrm{cD}}$ & $38.73 \pm 0.22^{\mathrm{dD}}$ & $59.68 \pm 0.89^{\mathrm{bC}}$ & $71.06 \pm 0.17^{\mathrm{bB}}$ & $86.73 \pm 0.33^{\mathrm{cA}}$ \\
\hline Retrograded potato & $35.18 \pm 0.93^{\mathrm{aG}}$ & $43.74 \pm 0.09^{\mathrm{aF}}$ & $44.67 \pm 0.37^{\mathrm{bE}}$ & $51.48 \pm 0.43^{\mathrm{bD}}$ & $55.01 \pm 0.19^{\mathrm{cC}}$ & $66.05 \pm 0.36^{\mathrm{cB}}$ & $69.43 \pm 0.43^{\mathrm{dA}}$ \\
\hline
\end{tabular}

Tarım Bilimleri Dergisi - Journal of Agricultural Sciences

25 (2019) 281-289 


\section{Conclusions}

The potato starch and its physically modified forms had higher UFW contents than those of the wheat starch and its physically modified forms in all the studied hydration levels. The UFW contents of the starch samples increased with increase in hydration level. The $\mathrm{T}_{\mathrm{o}}, \mathrm{T}_{\mathrm{p}}$ and $\mathrm{T}_{\mathrm{e}}$ values of the peak belonging to FW also increased with increasing hydration level. The lowest and the highest WAI were obtained in the native wheat and the gelatinized potato starches, respectively. A similar situation was also determined for the WSI values. Significant differences were found in all of the properties identified in starches, thus, further researches are needed for different starch combinations of this characteristic properties.

\section{References}

Alamri M S, Mohamed AA \& Hussain S (2013). Effects of alkaline-soluble okra gum on rheological and thermal properties of systems with wheat or corn starch. Food Hydrocolloids 30(2): 541-551

Alcazar-Alay S C \& Meireles M A A (2015). Physicochemical properties, modifications and applications of starches from different botanical sources. Food Science and Technology 35(2): 215236

Anderson R, Conway H, Pfeifer V \& Griffin E (1969). Gelatinization of corn grits by roll-and extrusioncooking. Cereal Science Today 14(1): 4-11

Ashogbon A O \& Akintayo E T (2014). Recent trend in the physical and chemical modification of starches from different botanical sources: A Review. StarchStarke 66(1-2): 41-57

Blazek J \& Copeland L (2009). Effect of monopalmitin on pasting properties of wheat starches with varying amylose content. Carbohydrate Polymers 78(1): 131136

Bogracheva T Y, Wang Y L, Wang T L \& Hedley C L (2002). Structural studies of starches with different water contents. Biopolymers 64(5): 268-281

Colussi R, Singh J, Kaur L, Zavareze E D, Dias A R G, Stewart R B \& Singh H (2017). Microstructural characteristics and gastro-small intestinal digestion in vitro of potato starch: effects of refrigerated storage and reheating in microwave. Food Chemistry 226: 171-178
Cozzolino D (2016). The use of the rapid visco analyser (rva) in breeding and selection of cereals. Journal of Cereal Science 70: 282-290

Eliasson A C \& Gudmundsson M (2006). Starch: Physicochemical and Functional Aspects. In: A C Eliasson (Ed.), Carbohydrates in Food, CRC/Taylor \& Francis, Boca Raton, pp. 391-469

Fredriksson H, Silverio J, Andersson R, Eliasson A C \& Aman P (1998). The Influence of Amylose and Amylopectin characteristics on Gelatinization and Retrogradation properties of different starches. Carbohydrate Polymers 35(3-4): 119-134

Fu Z Q, Wang L J, Zou H, Li D \& Adhikari B (2014). Studies on the starch-water interactions between partially gelatinized corn starch and water during gelatinization. Carbohydrate Polymers 101: 727-732

Gomand S V, Lamberts L, Visser R G F \& Delcour J A (2010). Physicochemical properties of potato and cassava starches and their mutants in relation to their structural properties. Food Hydrocolloids 24(4): 424433

Grunina N A, Tsereteli G I, Belopolskaya T V \& Smirnova O I (2015). Thermal properties of frozen water in the native and amorphous starches with various hydration degrees. Carbohydrate Polymers 132: 499-508

Gryszkin A, Zieba T \& Kapelko-Zeberska M (2016). Hydrothermal modification of wheat starch. part 2 . thermal characteristics of pasting and rheological properties of pastes. Journal of Cereal Science 69: 194-198

Hovenkamp-Hermelink J H M, Devries J N, Adamse P, Jacobsen E, Witholt B \& Feenstra W J (1988). Rapid estimation of the amylose amylopectin ratio in small amounts of tuber and leaf tissue of the potato. Potato Research 31(2): 241-246

Huang T T, Zhou D N, Jin Z Y, Xu X M \& Chen H Q (2015). Effect of debranching and heat-moisture treatments on structural characteristics and digestibility of sweet potato starch. Food Chemistry 187: 218-224

Huang T T, Zhou D N, Jin Z Y, Xu X M \& Chen H Q (2016). Effect of repeated heat-moisture treatments on digestibility, physicochemical and structural properties of sweet potato starch. Food Hydrocolloids 54: $202-210$

Jane J, Chen Y Y, Lee L F, Mcpherson A E, Wong K S, Radosavljevic M \& Kasemsuwan T (1999). Effects of amylopectin branch chain length and amylose content 
on the gelatinization and pasting properties of starch. Cereal Chemistry 76(5): 629-637

Kaur B, Ariffin F, Bhat R \& Karim A A (2012). Progress in starch modification in the last decade. Food Hydrocolloids 26(2): 398-404

Kaur L \& Singh J (2015). Starch: Modified starches. In: B Caballero, P Finglas \& F Toldra (Eds.), Encyclopedia of Food and Health, Elsevier Academic Press, Oxford, pp. 152-159

Ragaee S \& Abdel-Aal E S M (2006). Pasting properties of starch and protein in selected cereals and quality of their food products. Food Chemistry 95(1): 9-18

Singh N, Singh J, Kaur L, Sodhi N S \& Gill B S (2003). Morphological, Thermal and rheological properties of starches from different botanical sources. Food Chemistry 81(2): 219-231

Suzuki S \& Kitamura S (2008). Unfrozen Water in amylosic molecules is dependent on the molecular structures - a differential scanning calorimetric study. Food Hydrocolloids 22(5): 862-867

Tananuwong K \& Reid D S (2004). DSC and NMR Relaxation studies of starch-water interactions during gelatinization. Carbohydrate Polymers 58(3): 345358
Tang H R, Brun A \& Hills B (2001). A Proton NMR relaxation study of the gelatinisation and acid hydrolysis of native potato starch. Carbohydrate Polymers 46(1): 7-18

Wang H W, Zhang B J, Chen L \& Li X X (2016). Understanding the structure and digestibility of heatmoisture treated starch. International Journal of Biological Macromolecules 88: 1-8

Wang S J, Li C L, Yu J L, Copeland L \& Wang S (2014). Phase Transition and swelling behaviour of different starch granules over a wide range of water content. Lwt-Food Science and Technology 59(2): 597-604

Wang S J, Li C L, Copeland L, Niu Q \& Wang S (2015). Starch retrogradation: A comprehensive review. Comprehensive Reviews in Food Science and Food Safety 14(5): 568-585

Yglesias R \& Jackson D S (2005). Evaluation of liquid nitrogen freeze drying and ethanol dehydration as methods to preserve partially cooked starch and masa systems. Cereal Chemistry 82(6): 702-705

Zia-Ud-Din, Xiong H G \& Fei P (2017). Physical and chemical modification of starches: A Review. Critical Reviews in Food Science and Nutrition 57(12): 26912705 